\title{
Comparison of green turtle Chelonia mydas sex ratios at two time-points over 20 years at a foraging ground in Yaeyama Islands, Ryukyu Archipelago, Japan
}

\author{
Kazunari Kameda $^{1, *}$, Kazuyuki Suzuki $^{2}$, Kenji Kuroyanagi $^{3}$, Mai Takase $^{4}$, \\ Kazuya Matsuda ${ }^{2}$, Jun Noda ${ }^{2}$ \\ ${ }^{1}$ Kuroshima Research Station, Sea Turtle Association of Japan, 136 Kuroshima, Taketomi-Cho, Okinawa 907-1311, Japan \\ ${ }^{2}$ School of Veterinary Medicine, Rakuno Gakuen University, 582 Bunkyodai Midorimachi 470-3233, Ebetsu, \\ Hokkaido 069-8501, Japan \\ ${ }^{3}$ Minamichita Beach Land, Meitetsu Impress Co., Ltd, 428-1 Okuda, Mihama-cho, Aichi 470-3233, Japan \\ ${ }^{4}$ Graduate School of Agricultural and Life Sciences, The University of Tokyo, 1-1-1 Yayoi Bunkyo-ku, Tokyo 113-8657, Japan
}

\begin{abstract}
Sex ratio is an important factor in population dynamics as it influences the production of offspring; understanding the sex ratio of a given population is vital for the conservation of endangered species. In sea turtles, the sex of hatchlings is temperature dependent, with warmer incubation temperatures producing more female hatchlings. The rise in temperatures due to global warming may skew the sex ratios towards females. We studied the sex ratio of immature green turtles at a foraging ground in the Yaeyama Islands from 1997-1999 and from 2016-2017, using laparoscopy. The overall proportion of females was $68.2 \%(\mathrm{~N}=314)$, and proportions were not significantly different between $1997-1999(69.9 \% ; \mathrm{N}=183)$ and $2016-2017(65.6 \% ; \mathrm{N}=131)$. Thus, sex ratios have not changed at this site over the last 20 years, suggesting minor or no effect of global warming/environmental influences on this population. The small size class $(<55 \mathrm{~cm}$ straight carapace length [SCL]) was more female biased than the large size class ( $\geq 55 \mathrm{~cm} \mathrm{SCL}$ ) during both periods, which suggests the possibility of movement into or out of the foraging aggregation. Therefore, future research must clarify how the initial recruitment into the foraging aggregations, and the subsequent migrations affect sex ratios.
\end{abstract}

KEY WORDS: Green turtle $\cdot$ Sex ratio $\cdot$ Migration $\cdot$ Recruitment $\cdot$ Global warming

\section{INTRODUCTION}

The sex determination of sea turtles is temperature dependent. Previous studies have proposed $29-30^{\circ} \mathrm{C}$ as the pivotal temperatures for sex determination in sea turtles, within a general range of 27 to $31^{\circ} \mathrm{C}$ (review by Wibbels 2003). Exposure of embryos to higher temperatures within this range results in a higher ratio of female offspring, while exposure to lower temperatures within the range results in a higher ratio of males. An extreme bias towards one sex, e.g. complete feminization, could be a major

\footnotetext{
*Corresponding author: kuroshima@umigame.org
}

threat to the survival of species with temperaturedependent sex determination (Jensen et al. 2018). For example, one reason for the decline in the leatherback turtle population in Teregganu, Malaysia, was considered to be hatchery practices which led to high female hatchling production and reduced hatch success rates (Chan \& Liew 1996). Furthermore, population structure, mortality rate, and sex ratio are fundamental demographic parameters. Sex ratios provide information about the reproductive potential of a population (Tarsi \& Tuff 2012) and thus represent an important basis for estimating the size and pro-

() The authors 2019. Open Access under Creative Commons by Attribution Licence. Use, distribution and reproduction are unrestricted. Authors and original publication must be credited. 
ductivity of populations of endangered species, including sea turtles (Casale et al. 2006, National Research Council 2010).

Green turtles Chelonia mydas have a circumglobal distribution, but mainly occur in tropical and subtropical waters. They are listed as Endangered on the International Union for Conservation of Nature Red List (Seminoff 2004). Green turtle hatchlings inhabit pelagic waters for approximately 4 to 10 yr until they shift to occupy habitats in the neritic (shallow) zone. It has been estimated that green turtles require approximately $30 \mathrm{yr}$ to reach maturity, with immature individuals spending about $20 \mathrm{yr}$ in shallow foraging grounds (Zug et al. 2002, Balazs \& Chaloupka 2004). Many previous studies have focused on the size distribution and survival rate of sea turtles inhabiting the neritic zone (Bjorndal et al. 2000, 2003, Koch et al. 2007, Colman et al. 2015, Kameda et al. 2017). However, those studies did not investigate the sex ratios of different size classes because the sex of immature sea turtles cannot be determined by their external morphology (Wibbels 1999). Consequently, our understanding of the sex ratio of immature sea turtles remains limited (Rees et al. 2016). The most recent review of meteorological data (IPCC 2014) has confirmed that there is a trend toward global warming, and global warming is expected to cause sex-ratio shifts in species with temperature-dependent sex determination (Hammam et al. 2007). Monitoring the sex ratio of immature green sea turtles at foraging grounds is important since it could be utilized to predict a population's future reproductive potential.

Previous genetic studies revealed that green turtles at certain foraging grounds are composed of aggregations of many individuals originating from different rookeries (Bass et al. 2006, Nishizawa et al. 2013). Therefore, the sex ratio of green turtles at foraging grounds represents a mixture of hatchling sex ratios produced over many years from the source rookeries. Previous studies of foraging grounds across the globe generally demonstrate female-biased sex ratios (e.g. Wibbels 2003, Allen et al. 2015, Braun McNeill et al. 2016). Limpus et al. (2009) reported that the sex ratio of small immature turtles $(<65 \mathrm{~cm}$ curved carapace length, CCL) in Clack Reef, Australia, was more female biased than that of large immature turtles (>65 cm CCL) at the same site. Female bias in smallsized green turtles is considered an early sign of global warming (Limpus et al. 2009, Jensen et al. 2018) and the simultaneous warming of nesting beaches. Higher female sex ratios might also be due to warmer sand temperatures in unshaded areas of beaches, resulting in part from a poorly managed relocation of eggs to open beach locations (e.g. Limpus 1993, Van de Merwe et al. 2006, Jensen et al. 2016).

The growth, or maturation, of sea turtles is a slow process. Long-term data is required to assess changes in sex ratio at given sites over time, due to recruitment, immigration, and emigration. However, the research periods in previous studies on sex ratios in immature sea turtles generally span less than $10 \mathrm{yr}$ (Limpus et al. 2009, Delgado et al. 2010, Braun McNeill et al. 2016).

Our research group has been monitoring the coastal foraging areas of green turtles in the Yeayama Islands of Ryukyu Archipelago, Japan, since 1995. A female-biased sex ratio of green turtle hatchlings has been reported in Taiwan, which is located near the Yaeyama Islands (King et al. 2013). However, there are no previous records of studies conducted on the juvenile green turtle population inhabiting this foraging ground. We recorded the sex ratios of turtles using laparoscopy and histological methods in 1997-1999 and 20162017. This study presents the first report to assess the sex ratios of immature green turtles inhabiting the marine area of Ryukyu Archipelago, in which the sex ratios of immature green turtles are compared at 2 time-points covering a long (20 yr) period.

\section{MATERIALS AND METHODS}

\subsection{Study area}

The Yaeyama Islands are located at the southern end of the Ryukyu Archipelago, northwestern Pacific $\left(24^{\circ} 00^{\prime}-24^{\circ} 40^{\prime} \mathrm{N}, 122^{\circ} 45^{\prime}-124^{\circ} 30^{\prime} \mathrm{E}\right.$; Fig. 1), and have one of the largest coral reefs in Japan. Sea grass and sea algae flourish in the inner reefs, and immature green turtles inhabit these coastal areas for feeding (Kameda et al. 2017). Annual average air temperature is $24.9^{\circ} \mathrm{C}$, ranging from 20.5 to $29.7^{\circ} \mathrm{C}$ across seasons in 2017 (Ishigakijima Local Metrological Observatory; www.jma-net.go.jp/ishigaki/ menu/menuReport.html). Annual water temperature is $26.1^{\circ} \mathrm{C}$, ranging from $22.2^{\circ} \mathrm{C}$ to $29.7^{\circ} \mathrm{C}$ across seasons in 2016 (Ministry of Environment; www.e-monitoring.jp/spot.html). The Yaeyama Islands consist of 8 islands. Many beaches on these islands are used as green turtle nesting sites, with Iriomote Island being one of the largest nesting sites in Japan (Kamezaki 1989). 


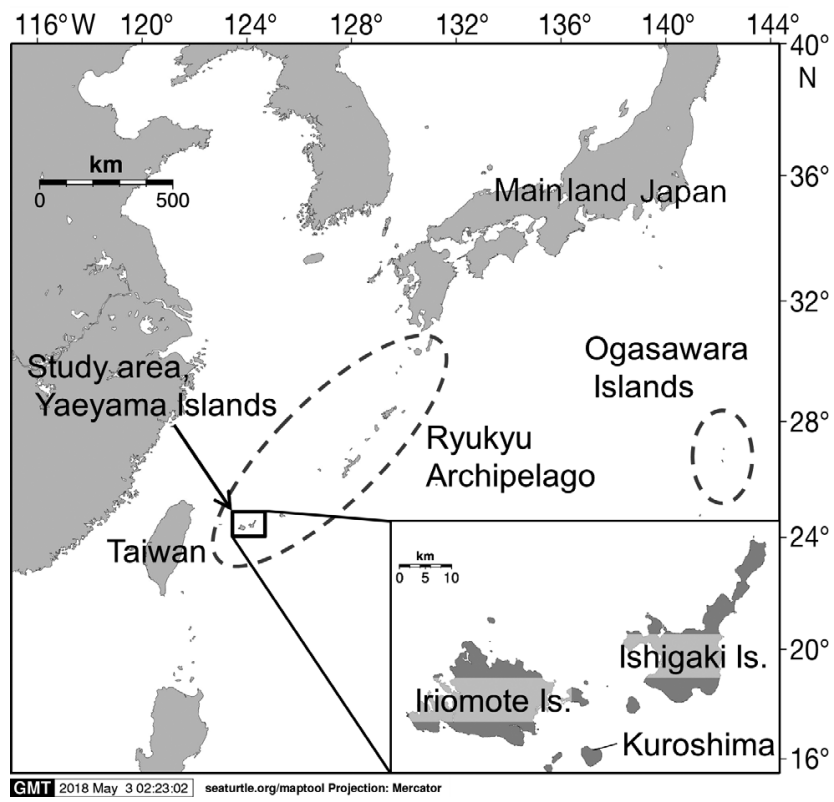

Fig. 1. Green sea turtle foraging grounds in Kuroshima, Yaeyama Islands. Dark grey dashed lines show the nesting sites of green turtles around the Yaeyama Islands and the Ogasawara Islands, Japan (Kamezaki 1989)

\subsection{Sea turtle capture and measurement}

Licensed sea turtle fishermen are allowed to legally catch green sea turtles, with a limit of 200 individuals per year, for local consumption in Yaeyama Islands. Throughout our study periods, from June 1997 to May 1999 and February 2016 to August 2017, licensed local fishermen captured turtles for our survey at intervals of 1 to 2 months. The local fishermen conducted snorkeling and dive surveys to search for and capture sea turtles, while the research team used entanglement nets $(200 \mathrm{~m}$ long, $2 \mathrm{~m}$ high, $40 \mathrm{~cm}$ mesh size) for their capture surveys. Captured turtles were transported within $3 \mathrm{~h}$ to an outdoor flow-through saltwater tank at the Kuroshima Research Station, which is located on Kuroshima, south Yaeyama Islands. Straight carapace length (SCL) was measured to the nearest $0.1 \mathrm{~cm}$ using metal calipers (Kamezaki \& Suganuma 1991). Turtles were tagged with an Inconel tag (Style 681; National Band and Tag Company) or a plastic tag (Jumbo tag; Dalton Tags) that was placed proximal to the first large scale on both rear flippers for a capture-markrecapture study. All turtles were released within 2 wk after the capture. All sampling procedures were permitted by the Marine Fisheries Coordinating Committee of Okinawa Prefecture, Japan (Approval \#K28-4, K29-4).

\subsection{Laparoscopy and sex determination}

Sex determination by laparoscopy was performed by trained veterinarians and scientists as previously described by Owens (1999). The mean time between arrival at Kuroshima Research Station and laparoscopy was $7 \mathrm{~d}$ (range: 2-21 d). Specifically, $1 \mathrm{ml}$ of anesthetic (Midazolam solution; Sandoz) per $5 \mathrm{~kg}$ body weight was injected into the pectoralis major muscle from the base of the front flipper. The sea turtle was restrained in an inverted position and a $1-2 \mathrm{~cm}$ incision was made on the peritoneal wall of the inguinal area. A laparoscope was inserted into the incision and the gonads were observed (Fig. 2). Sex was verified visually by the presence or absence of follicles, overall gonad coloration, and shape (Miller \& Limpus 2003). The incision was sealed with 2 or 3 stiches of self-dissolving catgut. The turtles were kept in a dry room in the Kuroshima Research Station for $6 \mathrm{~h}$ and then returned to the water tank. Sea turtles were monitored for abnormal
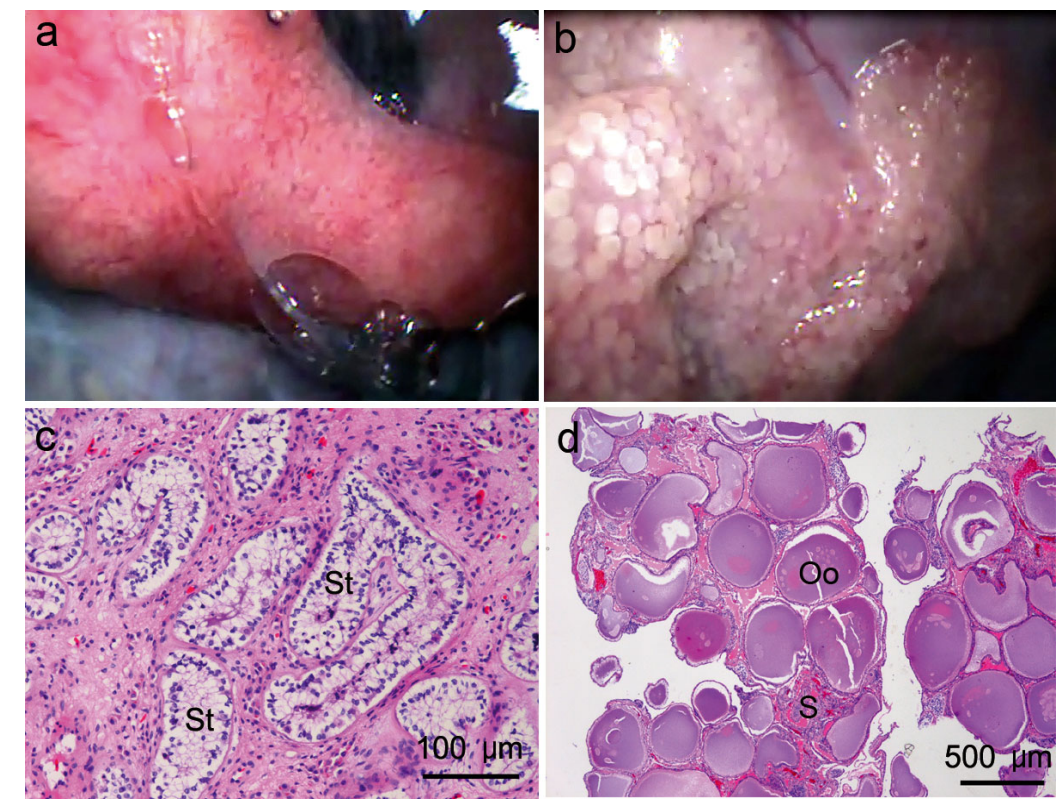

Fig. 2. $(\mathrm{a}, \mathrm{b})$ Photographs and $(\mathrm{c}, \mathrm{d})$ histology of $(\mathrm{a}, \mathrm{c})$ testis and $(\mathrm{b}, \mathrm{d})$ ovaries, obtained during the present study in 2016-2017. St: seminiferous tubules; Oo: oocytes; S: stroma. Staining in $(\mathrm{c}, \mathrm{d})$ : hematoxylin and eosin 
swimming behavior and were returned to the sea after recovery, which was within $14 \mathrm{~d}$. The laparoscope used in 1997 to 1999 had a diameter of $3.5 \mathrm{~mm}$ and a length of $280 \mathrm{~mm}$ (NCS-3427D, Olympus). A different laparoscope with a diameter of $10 \mathrm{~mm}$ and length of $270 \mathrm{~mm}$ was used in 2016 to 2017 (A5252A, Olympus). Model A5252A allowed biopsies to be conducted, with 1 to $3 \mathrm{~mm}$ of gonads being collected from sea turtles to obtain histological evidence (validation) of sex. Biopsy samples were fixed in $10 \%$ formalin, and paraffin-embedded tissue sections were prepared routinely. Each section was stained with hematoxylin and eosin. Tissue slides were observed under a microscope (Nikon ECLIPSE 80i) to check for the presence of oocytes or seminiferous tubules (Fig. 2). Laparoscopy in 2016-2017 was based on guidelines for animal experiments from the School of Veterinary Medicine, Rakuno Gakuen University, Japan (Approval \#VH16D2).

\subsection{Statistical analysis}

A study from Ogasawara Islands reported the mean size of mature green turtles as $91 \mathrm{~cm}$ for males and $95 \mathrm{~cm}$ SCL for females (Tachikawa 1991). We based our analysis on this finding, and sea turtles with SCL $>90 \mathrm{~cm}$ were thus considered to be mature and were removed from the analysis. The sex ratios in 1997-1999 and 2016-2017 and in each size class were compared using a chi-squared test. Confidence intervals (CI) of sex ratios were calculated using binomial distribution (Zar 1999). $\chi^{2}$ was calculated using Excel (Microsoft).

\section{RESULTS}

A total of 314 immature turtles were captured from the foraging grounds in the Yaeyama Islands in 1997-1999 and 2016-2017 (Table 1). The overall proportion of females was $68.2 \%$ (95\% CI: $62.7-73.3 \%, \mathrm{~N}=314)$, with a significant female bias $\left(\chi^{2}=41.4\right.$, $\mathrm{df}=1, \mathrm{p}<0.01, \mathrm{~N}=314)$. Sex ratios in 1997-1999 were more female biased than in 2016-2017, but no statistical difference was observed $\left(\chi^{2}=0.64\right.$, $\mathrm{df}=1, \mathrm{p}=0.42, \mathrm{~N}=314)$.
In 1997-1999, 56 males and 130 females were captured. The annual sex ratios in this period were not significantly different from each other $\left(\chi^{2}=2.26\right.$, $\mathrm{df}=2, \mathrm{p}=0.32, \mathrm{~N}=183$ ). In 2016-2017, 45 males and 86 females were captured and again there were no significant differences among years in the annual sex ratios $\left(\chi^{2}=0.006, d f=1, p=0.94, N=131\right)$

Overall, 56 gonad biopsy samples $(17.6 \%$ of all turtles) were collected for histological validation in 2016-2017. Samples were distinguished as being 19 males and 37 females, all of which matched the laparoscopy sex determinations (i.e. validated our observations).

The mean SCL was $53.3 \mathrm{~cm}(\mathrm{SD}=8.7$, range $=$ $36.2-89.3, \mathrm{~N}=183)$ in $1997-1999$ and $55.5 \mathrm{~cm}(\mathrm{SD}=$ 8.9 , range $=37.5-87.7, \mathrm{~N}=131$ ) in $2016-2017$. The size distribution of turtles was skewed toward smaller turtles (Fig. 3). Fig. 3 shows that sex ratios were female biased at $<55.0 \mathrm{~cm}$ SCL (small size class), but were close to equal at $\geq 55.0 \mathrm{~cm}$ SCL (large size class) in both study periods (Fig. 3, Table 1b). Overall, across the study period, there were 48 males and 150 females in the small size class $(75.8 \%$ female), and 52 males and 64 females $(55.2 \%$ female) in the large size class (Table 1), with the sex ratio of smaller turtles more skewed toward females than that of the larger turtles $\left(\chi^{2}=14.2, \mathrm{df}=1, \mathrm{p}<\right.$ $0.01, \mathrm{~N}=314)$.

Table 1. Sex ratio (male:female) composition of foraging green turtles in 1997-1999 and 2016-2017 by year and size class (straight carapace length, $\mathrm{SCL}$, in $\mathrm{cm}$ ). $95 \%$ confidence limits (CI) for the proportion of females to males are also shown. Overall refers to the values for both study periods combined

\begin{tabular}{|lcccccc|}
\hline & N & Male & Female & $\begin{array}{c}\text { Sex } \\
\text { ratio }\end{array}$ & $\begin{array}{c}\text { Proportion of } \\
\text { females (\%) }\end{array}$ & $95 \%$ CI \\
\hline Year & & & & & & \\
1997 & 118 & 31 & 87 & $1.0: 2.8$ & 73.7 & $64.8-81.4$ \\
1998 & 43 & 16 & 27 & $1.0: 1.7$ & 62.8 & $46.7-77.0$ \\
1999 & 22 & 8 & 14 & $1.0: 1.8$ & 63.6 & $40.7-82.8$ \\
Total 1997-1999 & 183 & 55 & 128 & $1.0: 2.3$ & 69.9 & $62.7-76.5$ \\
2016 & 46 & 16 & 30 & $1.0: 1.9$ & 65.2 & $49.8-78.6$ \\
2017 & 85 & 29 & 56 & $1.0: 1.9$ & 65.9 & $54.8-75.8$ \\
Total 2016-2017 & 131 & 45 & 86 & $1.0: 1.9$ & 65.6 & $56.9-73.7$ \\
Overall & 314 & 100 & 214 & $1.0: 2.1$ & 68.2 & $62.7-73.3$ \\
Size class (SCL, cm) & & & & & & \\
$1997-1999$ & 127 & 30 & 97 & $1.0: 3.1$ & 76.4 & $68.0-83.5$ \\
$<55$ & 56 & 25 & 31 & $1.0: 1.2$ & 55.4 & $41.5-68.7$ \\
$\geq 55$ & & & & & & \\
$2016-2017$ & 71 & 18 & 53 & $1.0: 2.9$ & 74.6 & $62.9-84.2$ \\
$\quad<55$ & 60 & 27 & 33 & $1.0: 1.2$ & 55.0 & $41.6-67.9$ \\
$\geq 55$ & & & & & & \\
Overall & 198 & 48 & 150 & $1.0: 3.1$ & 75.8 & $69.2-81.6$ \\
$\quad<55$ & 116 & 52 & 64 & $1.0: 1.2$ & 55.2 & $45.7-64.4$ \\
$\geq 55$ & & & & & &
\end{tabular}



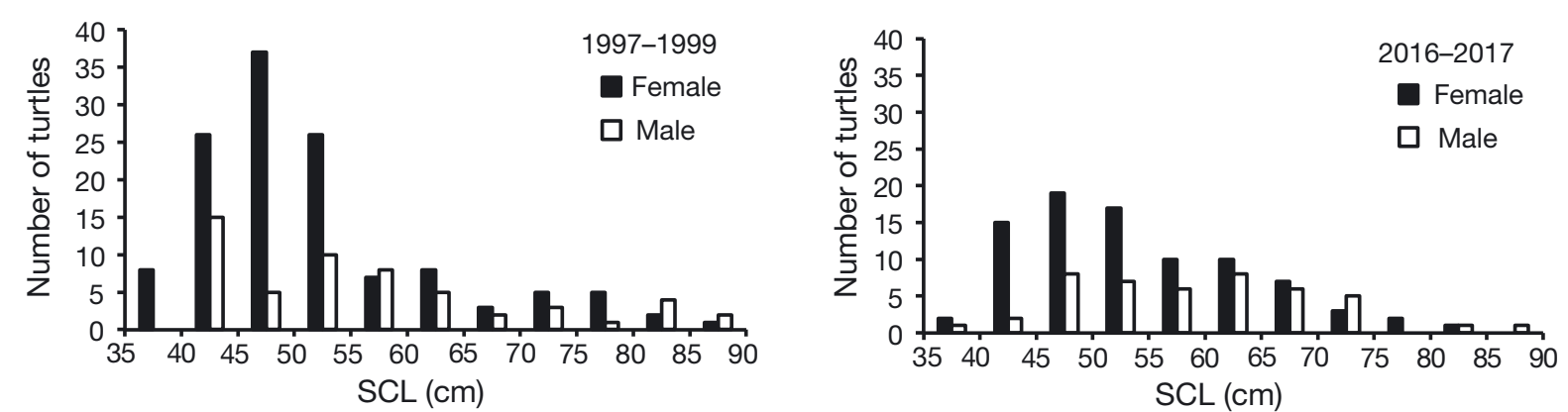

Fig. 3. Size distribution and sex of green turtles at foraging grounds in Yaeyama Islands, Japan (N = 183 in 1997-1999; $\mathrm{N}=131$ in 2016-2017)

\section{DISCUSSION}

The overall proportion of females was $69.9 \%$ in 1997-1999 and $65.9 \%$ in 2016-2017; thus, the proportion of females did not increase. Our results show that the small size class had a greater female bias than the large size class in both 1997-1999 and 2016-2017. Annual growth rates of immature green turtles are $2.7 \mathrm{~cm}$ on Yaeyama Island (Kameda et al. 2017), so green turtles measuring $40 \mathrm{~cm} \mathrm{SCL}$ in 1997-1999 are likely to measure about $90 \mathrm{~cm}$ SCL after $20 \mathrm{yr}$. If this difference in sex ratio between the size classes in 1997-1999 is the result of a greater number of smaller-sized females, then the sex ratio for the large size class should be more female biased in 2016-2017 than in 1997-1999, provided the smaller-sized turtles from 1997-1999 remained in this foraging ground. However, the sex ratios of the large size class in both periods were similar. Therefore, our results indicate that sex ratios at this foraging ground have remained unchanged over the past $20 \mathrm{yr}$.

Limpus et al. (2009) reported that the sex ratio of the small size class of immature green turtles was 1 male $(\mathrm{M}): 4.2$ females $(\mathrm{F})$, while that of the large size class was $1 \mathrm{M}: 2.2 \mathrm{~F}$ at Clack reef, Australia. This difference in sex ratio might be an early sign of the effects of global warming, with higher temperatures in the nest skewing the bias of embryos and hatchlings towards females (Limpus et al. 2009). In addition, artificial incubation without shading results in greater female bias than some natural nesting beaches where cover from plant vegetation results in lower incubation temperatures (Limpus 1993, Van de Merwe et al. 2005). Thus, an increase in beach temperatures due to global warming might result in a greater female bias in small size classes of immature turtles in foraging grounds. Previous studies have proposed this possible effect of global warming. For example, Jensen et al. (2018) sug- gested that the high female sex ratio (99\% female) of juvenile green turtles in the rookeries of northern Australia is due to global warming. Additionally, predictions using air temperature and sand temperature indicate that the sex ratio of future hatchlings will be increasingly female biased for the same reason (Santidrían Tomillo et al. 2015, Laloë et al. 2016). However, our results demonstrated no change in sex ratio over different size classes and time. Therefore, it is unlikely that the different sex ratios in the immature size classes in this study were a result of increased temperatures due to global warming or artificial incubation.

A similar difference in the sex ratios of the immature size classes was also reported in the Bahamas (Bolten et al. 1992) and Shoalwater Bay, Australia (Limpus et al. 2005). Differences in sex-specific mortality and growth rate may explain the different sex ratios in immature size classes if mortality rates are higher in females than males or if females grow more slowly than males. However, differences in sexspecific growth rates and mortality rates were not observed among immature green turtles on foraging grounds in The Bahamas (Bolten et al. 1992) and the Great Barrier Reef (Limpus \& Chaloupka 1997, Chaloupka \& Limpus 2005). Like the Great Barrier Reef, the Yaeyama Islands are in the western Pacific, so it is possible that sex-specific mortality and growth rates of immature green turtles are similar in these 2 areas.

We propose 2 hypotheses to explain the different sex ratios of different class size demonstrated in this study. First, the migration of juvenile green turtles may differ with respect to sex. For instance, during the pelagic stage, Delgado et al. (2010) postulated that female loggerhead sea turtles migrate to neritic foraging grounds earlier than males in Madeira. In our study area, female green turtles of over $55 \mathrm{~cm}$ SCL might migrate to alternative foraging grounds, whereas males might remain in the Yaeyama Islands. 
Size and sex-specific capture-mark-recapture data, satellite telemetry, and isotope analysis are required to identify these possible differing trends. Second, the migration of immature green turtles might differ with respect to size class. Green turtles in Japan nest in the Ryukyu Archipelago, which includes the Yaeyama Islands, and on the Ogasawara Islands (Kamezaki 1989). A previous study based on genetic analysis showed that green turtles in the Yaeyama Islands in the $40-50 \mathrm{~cm}$ SCL size class mainly originated from the Yaeyama Islands, whereas those in the $50-70 \mathrm{~cm}$ SCL size class mainly originated from the Ogasawara Islands (Hamabata 2014). Green turtles in the $40 \mathrm{~cm}$ SCL size class recruit from pelagic waters to neritic habitat in the Yaeyama region (Kameda et al. 2017). Isotope analysis has shown that many immature green turtles in the Yaeyama Islands are migrants from mainland Japan (Shimada et al. 2014). Additionally, the northern foraging aggregations of green turtles from mainland Japan mainly originated from the Ogasawara Islands (Nishizawa et al. 2013, 2014). Thus, the sex ratios of individuals in the $40-50 \mathrm{~cm}$ SCL class might be a result of recruitment from the Yaeyama Islands, while the sex ratios in the $50-70 \mathrm{~cm}$ SCL class might be due to the immigration of individuals from the Ogasawara Islands. Differences in the sex ratios for the immature size classes might be driven by the different sex ratios of hatchlings produced at each rookery.

The annual sex ratios of sea turtle hatchlings are not stable, due to sand temperature change caused by air temperature and other climate factors (Wibbels 2003). Therefore, long-term research is needed to analyze the effect of global warming on sex ratios (Fuller et al. 2013). The sex ratio of turtles at foraging sites is determined by sea turtles that hatched at various rookeries and migrated to the region over years to decades (Wibbels 2003). Differences in the sex ratios of immature size classes might thus be driven by the different sex ratios of hatchlings produced at the various source rookeries. An understanding of the sex ratio at the foraging grounds may enable an investigation of the effects of global warming on sea turtle sex ratios in the past few decades (e.g. Jensen et al. 2018). Our results propose that sex ratios at foraging grounds reflect not only primary recruitment but also immigration and emigration at later growth stages. Hatchling feminization may occur on a particular nesting beach, but this phenomenon will be neutralized at foraging sites if other nesting beaches produce more male hatchings. The detection of change in sex ratio due to global warming may require the use of multiple research techniques (e.g. genetics and endocrinology, Jensen et al. 2018). Future research should consist of long-term studies that focus on revealing the sex ratios of hatchlings produced from the Yaeyama Islands and Ogasawara Islands to understand how the sex ratio changes as sea turtles mature in the foraging grounds of the Yaeyama Islands. In addition, assessment of immature green turtle sex ratios at foraging grounds around the Yeyama Islands, i.e. Taiwan and the Japanese mainland, should be incorporated to clarify sexspecific migrations from those regions.

Acknowledgements. We especially thank the late Mr. Seiso Higa and Mr. Seiei Shimoji, local fishermen in Ishigaki Island, for their tireless efforts to capture green turtles. We also thank Dr. Naoki Kamezaki, Dr. Yoshimasa Matsuzawa, Mr. Fumito Iwase and Mr. Motoki Wakatsuki for all their support and advice. We are grateful to the anonymous reviewers for their work and efforts to improve this manuscript. We also acknowledge the use of the Maptool (www. seaturtle.org/) program for the maps of the study site. The field work was funded by Charitable Trust Taisei Corporation Natural and Historical Environment Fund and Okinawa Prefecture.

\section{LITERATURE CITED}

Allen CD, Robbins MN, Eguchi T, Owens DW and others (2015) First assessment of the sex ratio for an east Pacific green sea turtle foraging aggregation: validation and application of a testosterone ELISA. PLOS ONE 10: e0138861

Balazs GH, Chaloupka M (2004) Spatial and temporal variability in somatic growth of green sea turtles (Chelonia mydas) resident in the Hawaiian Archipelago. Mar Biol 145:1043-1059

Bass AL, Epperly SP, Braun-McNeill J (2006) Green turtle (Chelonia mydas) foraging and nesting aggregations in the Caribbean and Atlantic: impact of currents and behavior on dispersal. J Hered 97:346-354

Bjorndal KA, Bolten AB, Chaloupka MY (2000) Green turtle somatic growth model: evidence for density dependence. Ecol Appl 10:269-282

Bjorndal KA, Bolten AB, Chaloupka MY (2003) Survival probability estimates for immature green turtles Chelonia mydas in the Bahamas. Mar Ecol Prog Ser 252: 273-281

* Bolten AB, Bjorndal KA, Grumbles JS, Owens DW (1992) Sex ratios and sex-specific growth rates of immature green turtles, Chelonia Mydas, in the southern Bahamas. Copeia 1992:1098-1103

Braun McNeill J, Avens L, Goodman Hall A, Goshe LR, Harms CA, Owens DW (2016) Female-bias in a longterm study of a species with temperature-dependent sex determination: monitoring sex ratios for climate change research. PLOS ONE 11: e0160911

Casale P, Lazar B, Pont S, Tomás J and others (2006) Sex ratios of juvenile loggerhead sea turtles Caretta caretta in the Mediterranean Sea. Mar Ecol Prog Ser 324: 281-285 
Chaloupka M, Limpus C (2005) Estimates of sex-and ageclass specific survival probabilities for a southern Great Barrier Reef green sea turtle population. Mar Biol 146: 1251-1261

Chan EH, Liew HC (1996) Decline of the leatherback population in Terengganu, Malaysia, 1956-1995. Chelonian Conserv Biol 2:196-203

Colman LP, Patricio ARC, McGowan A, Santos AJB, Marcovaldi MA, Bellini C, Godley BJ (2015) Long-term growth and survival dynamics of green turtles (Chelonia mydas) at an isolated tropical archipelago in Brazil. Mar Biol 162: $111-122$

Welgado C, Canario AVM, Dellinger T (2010) Sex ratios of loggerhead sea turtles Caretta caretta during the juvenile pelagic stage. Mar Biol 157:979-990

Fuller WJ, Godley BJ, Hodgson DJ, Reece SE, Witt MJ, Broderick AC (2013) Importance of spatio-temporal data for predicting the effects of climate change on marine turtle sex ratios. Mar Ecol Prog Ser 488:267-274

Hamabata T (2014) Studies on the population genetic structure of green turtles (Chelonia mydas) nesting and foraging in the northwestern Pacific. PhD thesis, Kyoto University. https://oatd.org/oatd/img_viewer?record= handle \%5C\%3A2433\%2F188519\&img=page-0.png (in Japanese)

Hammam M, Limpus CJ, Read M (2007) Vulnerability of marine reptiles in the Great Barrier Reef to climate change. In: Johnson JE, Marshall PA (eds) Climate change and the Great Barrier Reef. A vulnerability assessment. Great Barrier Reef Marine Parks Authority, Townsville, p 465-496

IPCC (Intergovernmental Panel on Climate Change) (2014) Climate change 2014: Synthesis report. Contribution of working groups I, II and III to the Fifth Assessment Report of the Intergovernmental Panel on Climate Change. Core Writing Team, Pachauri RK, Meyer LA (eds) IPCC, Geneva

Jensen MP, Pilcher N, FitzSimmons NN (2016) Genetic markers provide insight on origins of immature green turtles Chelonia mydas with biased sex ratios at foraging grounds in Sabah, Malaysia. Endang Species Res 31: 191-201

Jensen MP, Allen CD, Eguchi T, Bell IP and others (2018) Environmental warming and feminization of one of the largest sea turtle populations in the world. Curr Biol 28: 154-159

Kameda K, Wakatsuki M, Kuroyanagi K, Iwase F and others (2017) Change in population structure, growth and mortality rate of juvenile green turtle (Chelonia mydas) after the decline of the sea turtle fishery in Yaeyama Islands, Ryukyu Archipelago. Mar Biol 164:143

Kamezaki K (1989) The nesting sites of sea turtles in the Ryukyu Archipelago and Taiwan. In: Matsui M, Hikida $\mathrm{T}$, Goris R (eds) Current herpetology in East Asia. The Herpetological Society of Japan, Kyoto, p 342-348

Kamezaki N, Suganuma H (1991) Summary of the First Japanese Sea Turtle Meeting in Kaogoshima. Umigame Newsl 7:114-119 (in Japanese)

King R, Cheng WH, Tseng CT, Chen H, Cheng IJ (2013) Estimating the sex ratio of green sea turtles (Chelonia mydas) in Taiwan by the nest temperature and histological methods. J Exp Mar Biol Ecol 445:140-147

Koch V, Brooks LB, Nichols WJ (2007) Population ecology of the green/black turtle (Chelonian mydas) in Bahia Magdalena, Mexico. Mar Biol 153:35-46
Kaloë JO, Esteban N, Berkel J, Hays GC (2016) Sand temperatures for nesting sea turtles in the Caribbean: implications for hatchling sex ratios in the face of climate change. J Exp Mar Biol Ecol 474:92-99

Limpus C (1993) Recommendations for conservation of marine turtles in Peninsula Malaysia. Report to Department of Fisheries, Ministry of Agriculture, Malaysia. Queensland Department of Environment and Heritage, Brisbane

* Limpus C, Chaloupka M (1997) Nonparametric regression modelling of green sea turtle growth rates (southern Great Barrier Reef). Mar Ecol Prog Ser 149:23-34

Limpus CJ, Limpus DJ, Arther KE, Parmenter CJ (2005) Monitoring green turtle population dynamics in Shoalwater Bay: 2000-2004. Queensland Environmental Protection Agency and the Great Barrier Reef Marine Park Authority, Townsville

Limpus CJ, Bell I, Miller JD (2009) Mixed stocks of green turtles foraging on Clack reef, northern Great Barrier Reef identified from long term tagging studies. Mar Turtle Newsl 123:3-5

Miller JD, Limpus CJ (2003) Ontogeny of marine turtle gonads. In: Lutz P, Musick J, Wyneken J (eds), Biology of sea turtles, Vol 2. CRC Press, Boca Raton, FL, p 199-224

National Research Council (2010) Assessment of sea-turtle status and trends: integrating demography and abundance. National Academy Press, Washington, DC

*Nishizawa N, Naito Y, Suganuma H, Abe O and others (2013) Composition of green turtle feeding aggregations along the Japanese archipelago: implications for changes in composition with current flow. Mar Biol 160: 2671-2685

Nishizawa N, Narazaki T, Fukuoka T, Sato K, Hamabata T, Kinoshita M, Arai N (2014) Juvenile green turtles on the northern edge of their range: mtDNA evidence of longdistance westward dispersals in the northern Pacific Ocean. Endang Species Res 24:171-179

Owens DW (1999) Reproductive cycles and endocrinology. In: Eckert KL, Bjorndal KA, Abreu-Grobois FA, Donnelly $M$ (eds) Research and management techniques for the conservation of sea turtles. IUCN/SSC Marine Turtle Specialist Group Publication 4:119-123

* Rees AF, Alfaro-Shigueto J, Barata PCR, Bjorndal KA, Bolten $A B$ and others (2016) Are we working towards global research priorities for management and conservation of sea turtles? Endang Species Res 31:337-382

* Santidrían Tomillo P, Genovart M, Paladino FV, Spotila JR, Oro D (2015) Climate change overruns resilience conferred by temperature-dependent sex determination in sea turtles and threatens their survival. Glob Change Biol 21:2980-2988

Seminoff JA (2004) Chelonia mydas. The IUCN Red List of Threatened Species 2004: e.T4615A11037468. http://dx. doi.org/10.2305/IUCN.UK.2004.RLTS.T4615A11037468.en

Shimada T, Aoki S, Kameda K, Hazel J, Reich K, Kamezaki N (2014) Site fidelity, ontogenetic shift and diet composition of green turtles Chelonia mydas in Japan inferred from stable isotope analysis. Endang Species Res 25: 151-164

Tachikawa H (1991) Carapace length and body weight of adult green turtle in Ogasawa. Umigame Newsl 8: 128-131 (in Japanese)

Tarsi K, Tuff T (2012) Introduction to population demographics. Nat Educ Knowl 3:3 www.nature.com/scitable/ knowledge/library/introduction-to-population-demographics-83032908 
Van de Merwe JP, Ibraham K, Whittier JM (2005) Effect of hatchery shading and nest depth on the development and quality of Chelonia mydas hatchlings: implications for hatchery management in Peninsular Malaysia. Aust J Zool 53:205-211

Van de Merwe JP, Ibrahim K, Whittier JM (2006) Effects of nest depth, shading, and metabolic heating on nest temperatures in sea turtle hatcheries. Chelonian Conserv Biol 5:210-215

Wibbels T (1999) Diagnosing the sex of sea turtles in foraging habitats. In: Eckert KL, Bjorndal KA, AbreuGrobois FA, Donnelly M (eds) Research and manage-

Editorial responsibility: Paolo Casale, Pisa, Italy ment techniques for the conservation of sea turtles. IUCN/SSC Marine Turtle Specialist Group Publication $4: 139-143$

Wibbels T (2003) Critical approaches to sex determination in sea turtles. In: Lutz PL, Musick JA, Wyneken J (eds) The biology of sea turtles, Vol 2. CRC Press, Boca Raton, FL, p 103-134

Zar JH (1999) Biostatistical analysis, 4th edn. Prentice-Hall, Upper Saddle River, NJ

Zug GR, Balazs GH, Wetherall JA (2002) Age and growth of Hawaiian green sea turtles (Chelonia mydas): an analysis based on skeletochronology. Fish Bull 100:117-127

Submitted: May 13, 2018; Accepted: January 25, 2019

Proofs received from author(s): February 27, 2019 